\title{
Opisthorchis felineus
}

National Cancer Institute

\section{Source}

National Cancer Institute. Opisthorchis felineus. NCI Thesaurus. Code C124356.

A species of trematode parasite in the family Opisthorchiidae characterized by a light brownish-to pink color, a cuticle lacking spines, and 2 prominent suckers, an oral sucker and a ventral one. The life cycle of $\mathrm{O}$. felineus involves freshwater snails as the first intermediate host, freshwater fish as the second intermediate host, and fish-eating mammals as the definitive host. Humans may become infested by eating undercooked fish. 